\title{
GENETIC ALGORITHMS APPLIED TO A FASTER DISTANCE PROTECTION OF TRANSMISSION LINES
}

\author{
Denis V. Coury* \\ coury@sc.usp.br
}

\author{
Mário Oleskovicz* \\ olesk@sc.usp.br
}

\author{
Silvio A. Souza* \\ sasouza@cteep.com.br \\ *SEL-EESC-USP São Carlos
}

Av. Trabalhador Sancarlense. 400 Centro

CEP 13566-590 - São Carlos - SP

\section{RESUMO}

Algorítmos Genéticos Aplicados a uma Mais Rápida Proteção de Distância de Linhas de Transmissão

O principal objetivo deste trabalho é implementar uma nova metodologia baseada em Algorítmos Genéticos (AGs) para extração de fasores fundamentais de tensão e corrente em sistemas que possibilite uma proteção de distância mais rápida. Os AGs resolvem problemas de otimização baseados nos princípios da seleção natural. Esta aplicação foi formulada como um problema de otimização, tendo como principal objetivo o de minimizar a estimação do erro entre as formas de ondas em análise. Uma linha de transmissão de $440 \mathrm{kV}$, com $150 \mathrm{~km}$ de extensão foi simulada através do software ATP (Alternative Transients Program) para testar a eficiência do novo método. Os resultados desta aplicação mostram que o desempenho geral do AG foi altamente satisfatório no que diz respeito a velocidade e a precisão na resposta quando comparado ao método tradicional utilizando a Transformada Discreta de Fourier.

PALAVRAS-CHAVE: Proteção de Distância, Transformada Discreta de Fourier, Linhas de Transmissão e Algorítmos Genéticos.

Artigo submetido em 23/02/2010 (Id.: 01106)

Revisado em 20/08/2010, 09/12/2010

Aceito sob recomendação do Editor Associado Prof. Julio Cesar Stacchini Souza

\section{ABSTRACT}

The main purpose of this paper is to implement a new methodology based on Genetic Algorithms (GAs) to extract the fundamental voltage and current phasors from noisy waves in power systems to be applied to a faster distance protection. GAs solve optimization problems based on natural selection principles. This application was then formulated as an optimization problem, and the aim was to minimize the estimation error. A 440 $\mathrm{kV}, 150 \mathrm{~km}$ transmission line was simulated using the ATP (Alternative Transients Program) software in order to show the efficiency of the new method. The results from this application show that the global performance of GAs was highly satisfactory concerning speed and accuracy of response, if compared to the traditional Discrete Fourier Transform (DFT).

KEYWORDS: Distance Protection, Discrete Fourier Transform, Transmission Lines and Genetic Algorithms.

\section{INTRODUCTION}

The increasing growth in power systems both in size and complexity has demanded higher speed relays in order to protect major equipment, as well as keeping its stability. When a fault occurs on a transmission line, radical changes occur in the voltage and current waveforms. The phase and magnitude of the $60 \mathrm{~Hz}$ voltage 
and current signals are badly corrupted by noise, in the form of a DC offset (exponentially decaying transient), as well as harmonic components. Therefore, a protective relaying system has to detect them as soon as possible and isolate the faulty region from the rest of the system, preventing the propagation of the fault.

Many research groups have been working on digital protection of transmission lines. Much attention has been paid to distance relaying techniques lately (Osman and Malik, 2001; Sidhu et al., 2002). Among many approaches considered, transmission line protection based on the fundamental frequency signals is widely used. Basically, the objective of a relaying scheme is to estimate the fundamental frequency components from the corrupted voltage and current signals following the fault occurrence. For distance relaying, these fundamental components are used to determine the apparent impedance (Phadke and Thorp, 1988). According to the calculated impedance, the fault is identified as internal or external to the protection zone.

Some filtering techniques found in the literature can be applied to this problem. Various digital signalprocessing techniques based on static and dynamic estimation have been suggested to evaluate the fundamental frequency $(60 \mathrm{~Hz})$. Some examples of static estimation are the Least-Squared Method (LSM) (Alfuhaid and ElSayed, 1999) and the Discrete Fourier Transform (DFT) (Altuve et al., 1996). On the other hand, the Kalman Filter is an example of a dynamic estimation (Girgis and Brown, 1985). Genetic Algorithms (GAs) (Osman et al., 2003a; Macedo et al., 2003) and Artificial Neural Networks (ANNs) (Osman et al., 2003b) have also been applied to the distance protection of power systems. However, the DFT filter has been the most popular for this purpose and has become a standard in the industry. This is because its computational cost is low and a good harmonic immunity can be reached. On the other hand, its performance can be adversely affected by the DC component leading to erroneous estimations, depending on the window length utilized. A shorter data window would give a faster response but an unstable output. A longer data window would give a stable result, but the response of the filter would be delayed. For protection purposes, a data window of one cycle has been largely used (Chen et al., 2006).

The main purpose of this paper is to implement a new methodology based on GAs to extract the fundamental voltage and current phasors in power systems to be applied to the distance protection. The optimization procedure follows an evolutionary strategy to find the best solution for a search problem. In order to obtain a faster distance protection decision, the window length for the new methodology was analyzed in comparison to the standard DFT filter, showing some advantages concerning the new approach.

\section{BASIC CONCEPTS RELATED TO GE- NETIC ALGORITHMS}

A Genetic Algorithm (GA) is a search algorithm based on the mechanism of natural selection and natural genetics. Its fundamental principle is "the fittest member of a population has the highest probability for survival". A GA operates in a population of current approximations, the individuals, initially drawn in a random order, from which improvement is sought. Individuals are encoded as strings, the chromosomes, so that their values represent a possible solution for a given optimization problem (Goldberge, 1989).

There is a fitness value associated to each chromosome. The better the solution the chromosome represents, the larger its fitness and its chances to survive and produce offspring. In this context, the objective function establishes the basis of selection.

At the reproduction stage, a fitness value is derived from the raw individual performance measure given by the objective function, as is used to bias the selection process. The selected individuals are then modified using genetic operators. Afterwards, individual chromosomes are decoded, evaluated, and selected according to their fitness, and the process continues for different generations. By manipulating a population of possible solutions simultaneously, the GAs can explore various areas of the search space.

The GAs rely on two basic kinds of operators: genetic and evolutionary. Genetic operators, namely crossover and mutation, are responsible for establishing how individuals exchange or simply change their genetic features in order to produce new individuals. Evolutionary operators deal with determining which individuals will experience crossover or mutation.

Essentially, a GA tries to minimize or maximize the value presumed by the fitness function. In many cases, the development of a fitness function can be based on this return and can represent only a partial evaluation of the problem. Additionally, the algorithm must be fast, because it will analyze each individual from a population and its successive generations. 


\section{THE REPRESENTATION OF THE ES- TIMATION PROBLEM}

\subsection{The mathematical model of the input signals}

A periodic signal can be represented as a sum of its exponential DC, the fundamental frequency, as well as its harmonic components. In order to estimate the harmonic components of a nonsinusoidal waveform, a mathematical expression can be written as (Pascual and Rapallini, 2001):

$$
x_{e}(t)=x_{0} e^{-\lambda \cdot t}+\sum_{i=1}^{N} A_{c, i} \cos \left(i w_{0} t\right)+A_{s, i} \sin \left(i w_{0} t\right)
$$

where $x_{0}$ is the amplitude of the decaying DC component and $\lambda$ is its time constant; and are the cosine and sine amplitudes of the $i^{t h}$ harmonic respectively; is the fundamental frequency $(377 \mathrm{rad} / \mathrm{sec}-60 \mathrm{~Hz})$ and $N$ is the number of harmonics used to represent $x(t)$.

Assuming that the signal $x_{s}(t)$ is sampled at a predefined time interval $\Delta t$, after $(m-1) * \Delta t$ seconds there will be $m$ samples, $x_{s}\left(t_{1}\right), x_{s}\left(t_{2}\right) \ldots x_{s}\left(t_{m}\right)$, for $t_{1}, t_{2} \ldots t_{m}$, where $t_{1}$ is an arbitrary time reference. The system of equations given by equation (2), where $e\left(t_{k}\right), k=1 \ldots \ldots m$, is the equation error at time $t_{k}$, and can be written as:

$$
\begin{aligned}
& \begin{array}{c}
{\left[\begin{array}{c}
x_{s}\left(t_{1}\right) \\
x_{s}\left(t_{2}\right) \\
\vdots \\
x_{s}\left(t_{m}\right)
\end{array}\right]=} \\
{\left[\begin{array}{cccc}
e^{-\lambda t_{1}} & \cdots & \cos \left(N w_{0} t_{1}\right) & \sin \left(N w_{0} t_{1}\right) \\
e^{-\lambda_{2}} & \cdots & \cos \left(N w_{0} t_{2}\right) & \sin \left(N w_{0} t_{2}\right) \\
\vdots & & \ddots & \vdots \\
e^{-\lambda t_{m}} & \cdots & \cos \left(N w_{0} t_{m}\right) & \sin \left(N w_{0} t_{m 1}\right)
\end{array}\right]}
\end{array} \\
& \cdot\left[\begin{array}{c}
x_{0} \\
A_{c, 1} \\
A_{s, 1} \\
\vdots \\
A_{c, N} \\
A_{s, N}
\end{array}\right]+\left[\begin{array}{c}
e\left(t_{1}\right) \\
e\left(t_{2}\right) \\
\vdots \\
e\left(t_{m}\right)
\end{array}\right]
\end{aligned}
$$

In this work, the system (2) is solved using GAs. Solving the system of equations given by (2), we would be able to find, $\lambda, x_{0}$, and , $i=1, \ldots, N$. However, concern- ing the distance protection application, only the fundamental phasors are required to calculate the apparent impedances seen by a local relay during a faulty situation. Therefore, equation (1) was drastically simplified considering only the cosine and sine amplitudes of the fundamental component, and, respectively. Taking this into account, a real-coded GA scheme was used to represent the cosine and sine amplitudes of the fundamental voltage and current, as illustrated in Figure 1. Considering this approach, the GA worked as a filter for the voltage and current inputs, which is well known for being corrupted by noise (as mentioned before).

\section{Chromosome real representation}

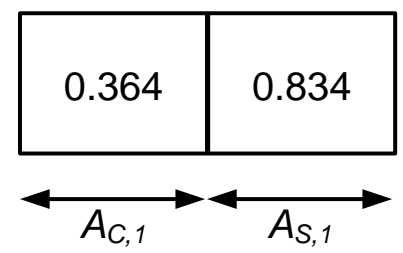

Figure 1: Individual representation.

\subsection{The fitness function}

The evaluation function $\left(F_{A}\right)$ is responsible for determining the fitness of each individual. Its objective is to evaluate the estimation error $(e)$, in $(3)$. The coded parameters in equation (2) are compared to the measured value in each time step in order to calculate the error (e) (Figure 2).

$$
e\left(t_{k}\right)=x_{s}\left(t_{k}\right)-x_{e}\left(t_{k}\right) \quad k=1 \ldots . m
$$

The error represented in (4) was used in this work.

$$
E_{T}=\sqrt{\frac{\left|\sum_{i=1}^{m} e_{i}\right|}{m}}
$$

As the objective of the GAs is to maximize the chromosome's fitness, it is necessary to transform $E_{T}$ into a fitness function $(\mathrm{F})$. This is done using equation (5) , where $\Delta$ is a very small positive constant, 0.00001 , aimed to avoid overflow problems.

$$
F_{A}=\frac{1}{E_{T}+\Delta}
$$

Concerning the reproduction process, some of the parameters should be mentioned, such as: population of 




Figure 2: The estimation error evaluation.

100 individuals, chromosomes with real representation, the tournament operator; the considered crossover and mutation rates of $90 \%$ and $10 \%$, respectively. The stop criterion in each run was 5,000 generations or 100 generations without improvement.

\subsection{The Discrete Fourier Transform}

Traditionally, the Fourier technique is widely used to analyze currents and voltage waveforms from an electric power system. In this work, the DFT technique is used in order to compare it to the new methodology proposed.

Considering the Fourier filter, the real and imaginary components of the fundamental frequency phasor (for one cycle of data with $N c$ samples per cycle), are given by the following equations (Pascual and Rapallini, 2001):

$$
\begin{gathered}
\hat{x} \text { or }=\frac{2}{N c} \sum_{n=0}^{N c-1} x(n) \cos \left(\frac{2 \pi n}{N c}\right) \\
\hat{x} \text { oi }=-\frac{2}{N c} \sum_{n=0}^{N c-1} x(n) \sin \left(\frac{2 \pi n}{N c}\right)
\end{gathered}
$$

where and are the peak value of the real and imaginary components of the fundamental frequency phasor of the input signal $x(n)$, respectively. For a half cycle and one quarter of a cycle, $2 / N c$ should be replaced by $4 / N c$ and $8 / N c$ in equations (4) and (5), respectively.

\section{TEST RESULTS}

\subsection{Transmission line simulation}

In order to obtain the voltage and current signals, which will be applied to distance protection, transmission lines with source equivalents at the ends were simulated (Figure 3). This work makes use of a digital simulator of faulted EHV (Extra High Voltage) transmission lines known as the Alternative Transients Program - ATP (ATP, 1987).

A typical $440 \mathrm{kV}$ transmission line, illustrated in Figure 4, from CESP (Companhia Energética de São Paulo - a Brazilian utility) was utilized.

It should be mentioned that although the technique described is based on Computer Aided Design (CAD), practical considerations such as the Capacitor Voltage Transformer (CVT) and Current Transformers (CT), anti-aliasing filters and quantisation on system fault data were also included in the simulation. The data obtained was very close to that found in practice. The technique also considered the physical arrangement of the conductors in the structure (Figure 4), the characteristics of the conductors, mutual coupling, and the effect of earth return path. Perfect line transposition was assumed.

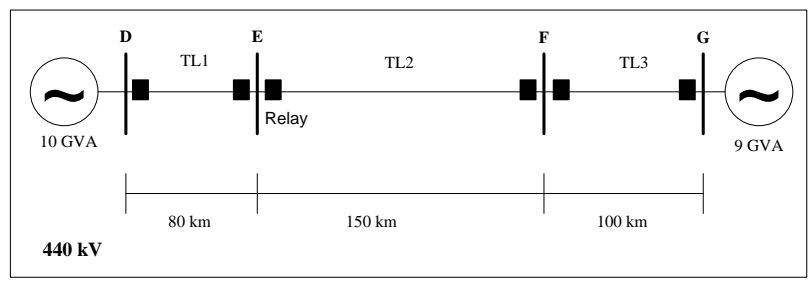

Figure 3: Power system simulated using ATP software.

The transmission line parameters are presented in Table 1. Tables 2 and 3 show the equivalent parameters concerning the generators and data from $D$ and $G$ terminals, respectively.

For this approach, the voltage and current fault values from busbar $E$ were utilised as inputs. A sampling frequency of $2.400 \mathrm{~Hz}$ to distance protection calculations was used.

The simulated data were obtained applying different faults in the TL2 transmission line $(150 \mathrm{~km})$ between busbars $E$ and $F$. 


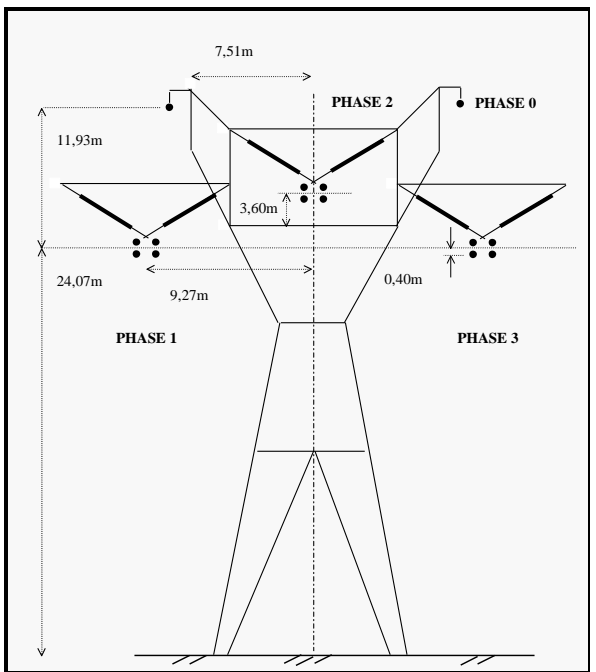

Figure 4: Transmission line structure $(440 \mathrm{kV})$.

Table 1: Transmission line parameters

\begin{tabular}{ccc}
\hline \multicolumn{3}{c}{ Positive Sequence } \\
$\mathbf{R}$ (ohms/km) & $\mathbf{L}(\mathbf{m H} / \mathbf{k m})$ & $\mathbf{C}(\mathbf{u F} / \mathbf{k m})$ \\
\hline $3.853 \mathrm{E}-02$ & $7.410 \mathrm{E}-01$ & $1.570 \mathrm{E}-02$ \\
\hline \multicolumn{3}{c}{ Negative Sequence } \\
$\mathbf{R}$ (ohms/km) & $\mathbf{L}(\mathbf{m H} / \mathbf{k m})$ & $\mathbf{C}(\mathbf{u F} / \mathbf{k m})$ \\
\hline $1.861 \mathrm{E}+00$ & $2.230 \mathrm{E}+00$ & $9.034 \mathrm{E}-03$ \\
\hline
\end{tabular}

Table 2: Equivalent parameters from $D$ and $G$ generation terminals

\begin{tabular}{lcc}
\hline & \multicolumn{2}{c}{ Generation Terminal $D$} \\
& Positive Seq. & Negative Seq. \\
\hline $\mathbf{R}(\mathbf{o h m s} / \mathbf{k m})$ & 1.6982 & 0.358 \\
\hline $\mathbf{L}(\mathbf{m H} / \mathbf{k m})$ & $5.14 \mathrm{E}+01$ & $1.12 \mathrm{E}+01$ \\
\hline \hline & \multicolumn{2}{c}{ Generation Terminal $G$} \\
& Positive Seq. & Negative Seq. \\
\hline $\mathbf{R}(\mathbf{o h m s} / \mathbf{k m})$ & 1.7876 & 0.4052 \\
\hline $\mathbf{L}(\mathbf{m H} / \mathbf{k m})$ & $5.41 \mathrm{E}+01$ & $1.23 \mathrm{E}+01$ \\
\hline \hline
\end{tabular}

Table 3: Data from $D$ and $G$ Generation Terminals

\begin{tabular}{lll}
\hline & $\begin{array}{l}\text { Generation } \\
\text { Terminal } D\end{array}$ & $\begin{array}{l}\text { Generation } \\
\text { Terminal } G\end{array}$ \\
\hline Power (GVA) & 10 & 9 \\
\hline Voltage (pu) & 1.05 & 0.95 \\
\hline Phase (grade) & 0 & -10 \\
\hline
\end{tabular}

Figures 5 and 6 show a typical situation of an a-phaseto-earth fault in the TL2 transmission line at $75 \mathrm{~km}$ from busbar $E$.

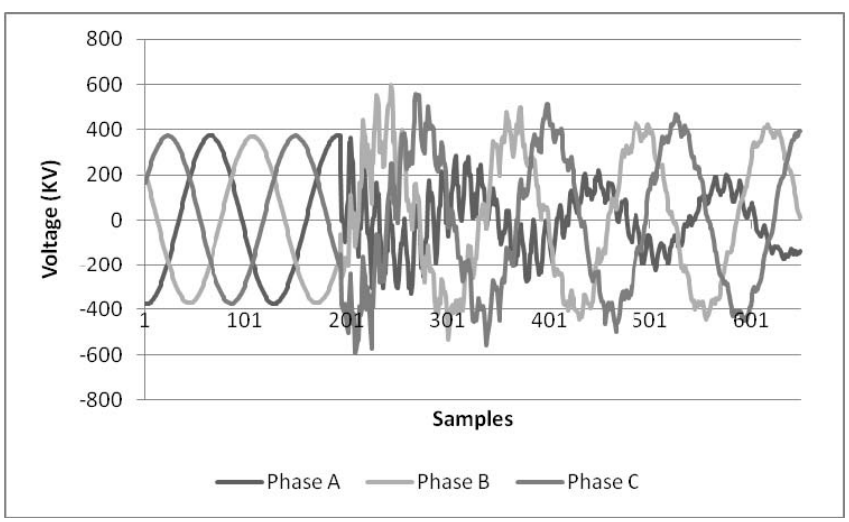

Figure 5: Voltage waveforms at the TL2 transmission line.

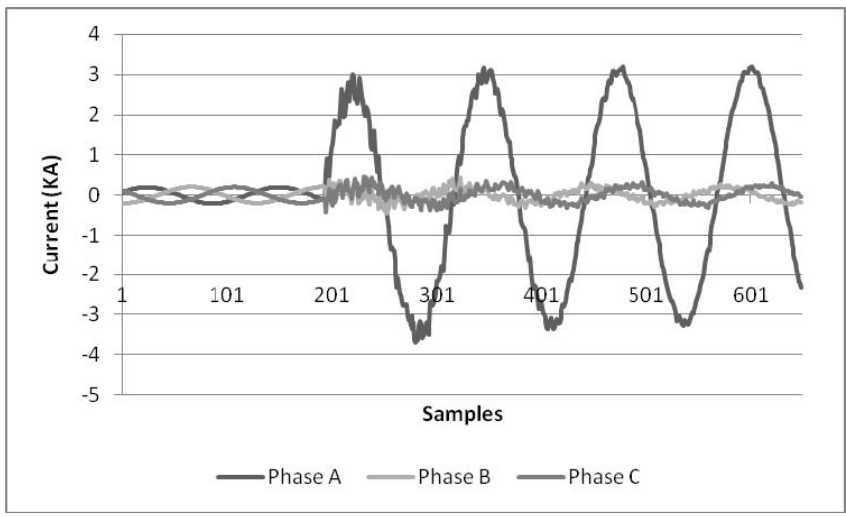

Figure 6: Current waveforms at the TL2 transmission line.

The obtained data (voltage and current waveforms) were filtered using a $2^{\text {nd }}$ order Butterworth filter with a cutoff frequency of $360 \mathrm{~Hz}$ in order to eliminate some of the high frequency components, as well as to prevent the aliasing effect. Moreover, the voltage and current waveforms were digitalized using a 12 bit analog to digital converter (ADC).

\subsection{Distance protection algorithm results}

Impedance relays are from the family of distance relays. They are used to calculate the apparent impedance up to the fault point by measuring voltages and currents at one single end. As is known, they compare the apparent impedance/fault distance measured to a protection zone to determine if a fault is inside or outside it.

A complete scheme for a distance protection relay is shown in Figure 7. The voltage and current signals come 
from the power system shown in Figure 3, simulated in the ATP software. The first step of the algorithm was the fault detection. Samples of current signals were stored in the memory. When a new sample came, it was compared to the corresponding sample one cycle earlier. If the change was bigger than 0,05 p.u and this change was confirmed by a counter four consecutive times, the fault situation was detected.

The next step was digital filtering. In this work, the traditional DFT, as well as an alternative method, Genetic Algorithms (GA), were utilized in order to estimate the fundamental frequency phasors, as shown in 7 . Both methodologies were used to appropriately estimate these phasors as discussed in section 3 .

The fault classification was also implemented because of the need to choose the voltages and currents involved in a fault adequately in order to correctly calculate the apparent impedance seen by the distance relay. The method adopted in the design consists of calculating the peak value of the three line currents and zero sequence current from the estimated states from the filters, as mentioned in Girgis and Brown (1985). Table 4 show the equations for fault impedance calculation according to the fault type (IEEE Std. C37.114 ${ }^{T M}$, 2004).

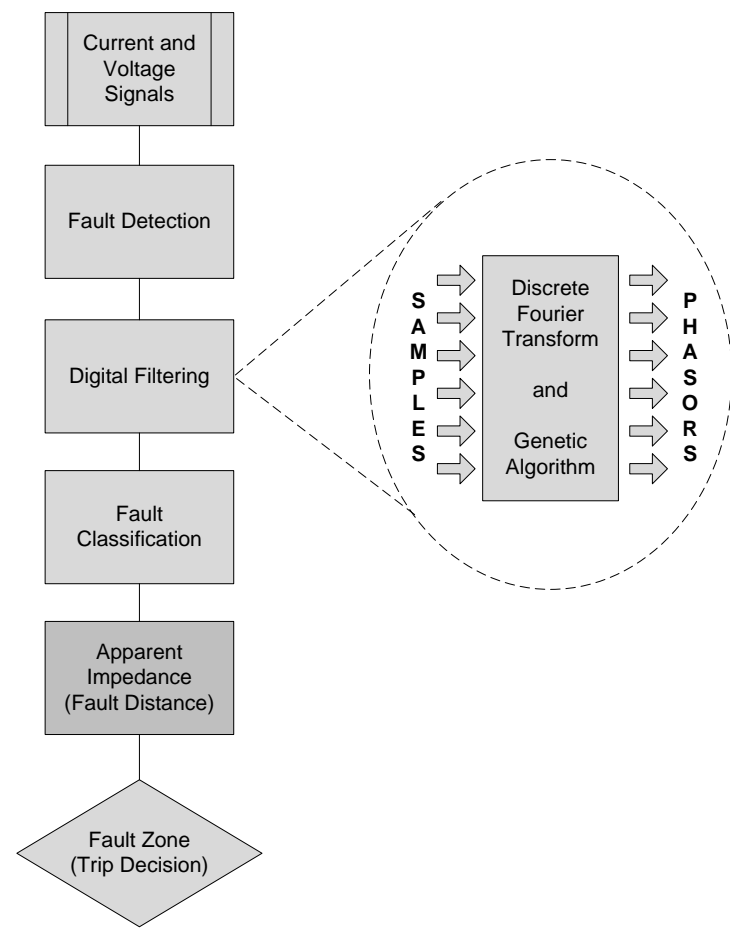

Figure 7: A basic diagram for a distance protection relay.

In Table 4, $A, B$ and $C$ indicate the phases involved, $G$ is for ground, $V$ and $I$ are voltage and current phasors, $k=$
Table 4: Fault impedance equations for different types of faults.

\begin{tabular}{c|c}
\hline Fault Type & Equation \\
\hline$A G$ & $\mathbf{V}_{A} /\left(\mathbf{I}_{A}+3 k \mathbf{I}_{0}\right)$ \\
\hline$B G$ & $\mathbf{V}_{B} /\left(\mathbf{I}_{B}+3 k \mathbf{I}_{0}\right)$ \\
\hline$C G$ & $\mathbf{V}_{C} /\left(\mathbf{I}_{C}+3 k \mathbf{I}_{0}\right)$ \\
\hline$A B$ or $A B G$ & $\left(\mathbf{V}_{A}-\mathbf{V}_{B}\right) /\left(\mathbf{I}_{A}-\mathbf{I}_{B}\right)$ \\
\hline$B C$ or $B C G$ & $\left(\mathbf{V}_{B}-\mathbf{V}_{C}\right) /\left(\mathbf{I}_{B}-\mathbf{I}_{C}\right)$ \\
\hline$C A$ or $C A G$ & $\left(\mathbf{V}_{C}-\mathbf{V}_{A}\right) /\left(\mathbf{I}_{C}-\mathbf{I}_{A}\right)$ \\
\hline$A B C$ & The same as a phase-to-phase \\
\hline
\end{tabular}

$\left(Z_{0}{ }^{\cup} Z_{1}\right) / Z_{1}, Z_{0}$ and $Z_{1}$ correspond to zero and positivesequence line impedance, respectively, and $I_{0}$ is the zerosequence current.

Finally, after the apparent impedance calculation, that is proportional to the distance to the fault, the protected zone is inferred.

Considering the power system shown in Figure 3, all types of faults were simulated in order to test the proposed technique compared to the traditional DFT filtering method. For brevity, the results presented are concentrated in line-to-ground faults (AG) and phaseto-phase faults. The system behavior for the other fault types is similar to those presented.

These different kinds of faults were obtained considering the TL2 transmission line in Figure 3. The distances considered from busbar $E$ were: 15, 45, 75, 105, 135 and $145 \mathrm{~km}$. The apparent impedances and fault distances were calculated for all kinds of faulty situations, taking into account not only the DFT but also the GA method. Windows of one, half and quarter of a cycle, i.e., 40, 20 and 10 samples from voltage and current waveforms were used as input for both methodologies. The fault inception angles for the simulations presented here were considered to be $0^{\circ}$ and $90^{\circ}$. Moreover, fault resistances of 0,50 and 100 Ohms were also included. Zone 1 was set to $80 \%$ of the total line length. Consequently, fault distances of $15,45,75$ and $105 \mathrm{~km}$ corresponded to the first zone and 135 and $145 \mathrm{~km}$ to the second zone.

Figure 8 shows the impedance trajectory from the preto the post-fault data, considering the use of a DFT filter (one and half cycle windows), as well as a GA filter of a quarter cycle. A single line to ground (SLG) fault was located in the middle of the line with no fault resistance for this case study.

Figures 9 to 14 show the stabilized values for the impedance calculation for different faults located along the line and different types of faults, considering the DFT and AG filtering methods. A standard quadrilateral characteristic for the first zone was adopted in the 


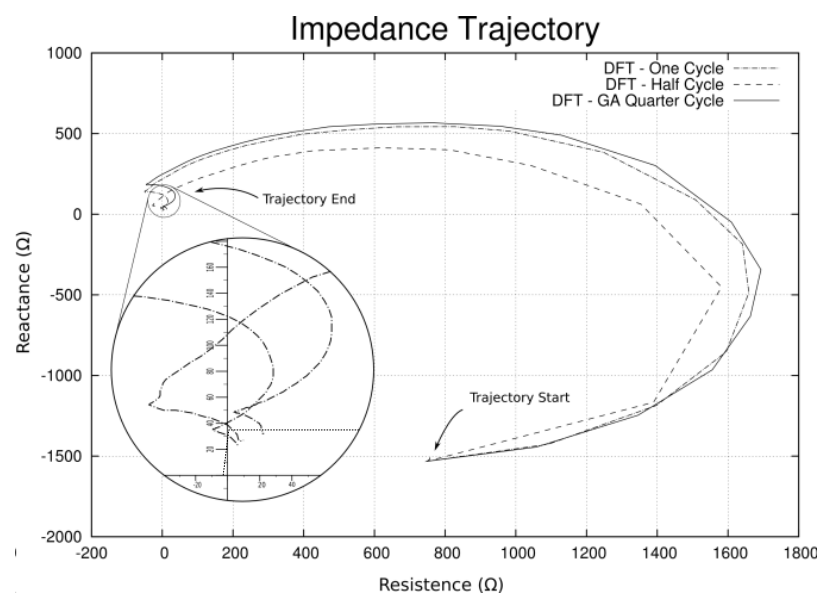

Figure 8: Impedance trajectory for a SLG (AG) fault considering DFT and AG filters.

figures as well as a representation for the positive sequence line in question.

Figure 9 illustrates the estimated apparent impedances using both DFT and GA filters, considering the distances described earlier along the line length versus the fault resistance variation for a single line to ground fault. The results show a good and correct estimation for both methods with one cycle data window.

Figure 10 illustrates the same situation using a half cycle data window. It can be observed that both methods presented similar results.

Finally, Figure 11 shows the same situation for a quarter cycle window. Considering the quarter cycle window of data, the use of GA shows a better result, especially because it kept the same type of response of the previous cases. The same did not happen with the DFT technique, as already expected.

The fault distance estimations, as well as the zone in which the faults are located (1- inside the primary zone and 0- otherwise), for the cases illustrated in Figures 9, 10 and 11 are shown in Table 5. The results are shown in function of the error calculated according to 8:

$$
e(\%)=\frac{\left|d_{\text {estimated }}-d_{\text {actual }}\right|}{L} * 100
$$

where, $d_{\text {estimated }}$ is the fault distance estimated by the GA; $d_{\text {actual }}$ is the actual fault distance; and $L$ is the total length of the transmission line.

It can be observed in Table 5 that generally the GA methodology shows a better performance (in terms of errors) if compared to the DFT method. This can be better observed in the cases using a quarter data window. For these cases, the fault distance estimations, as well as location zones, were on average much more precise, if compared to the traditional method, providing better conditions to the new method to distinguish different relay zones with this very short window.

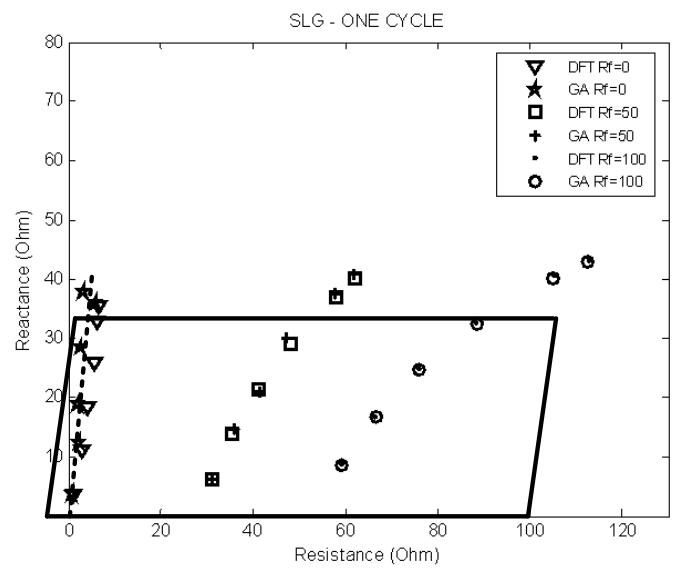

Figure 9: $\mathrm{R}-\mathrm{X}$ diagram for a SLG (AG) fault with 0,50 and 100 Ohms fault resistances and one cycle data window.

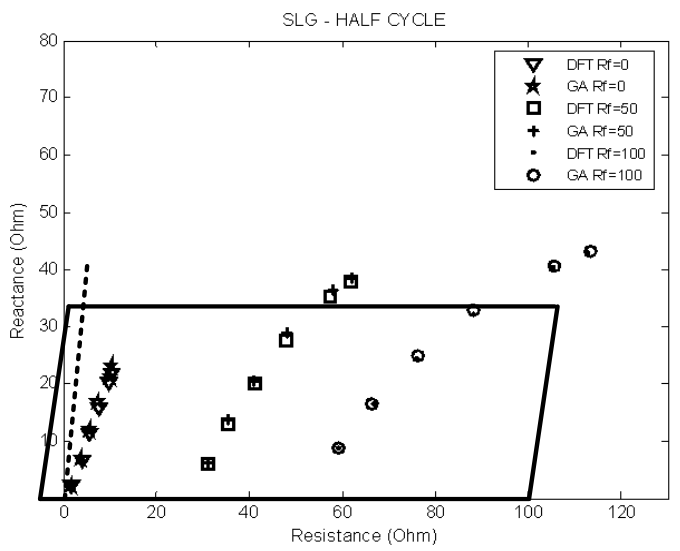

Figure 10: $\mathrm{R}-\mathrm{X}$ diagram for a SLG (AG) fault with 0, 50 and 100 Ohms fault resistances and half cycle data window.

Figure 12 presents a $\mathrm{R}-\mathrm{X}$ diagram for a double line fault $(\mathrm{AB})$ with fault resistance of $1 \mathrm{Ohm}$, considering a one cycle data window. A good estimation for both methods can be seen.

Figure 13 shows the same situation for a half cycle data window. Once more, both methods had approximately the same performance.

Finally, Figure 14 presents the same situation for a quarter data window. As shown, a better performance can be 


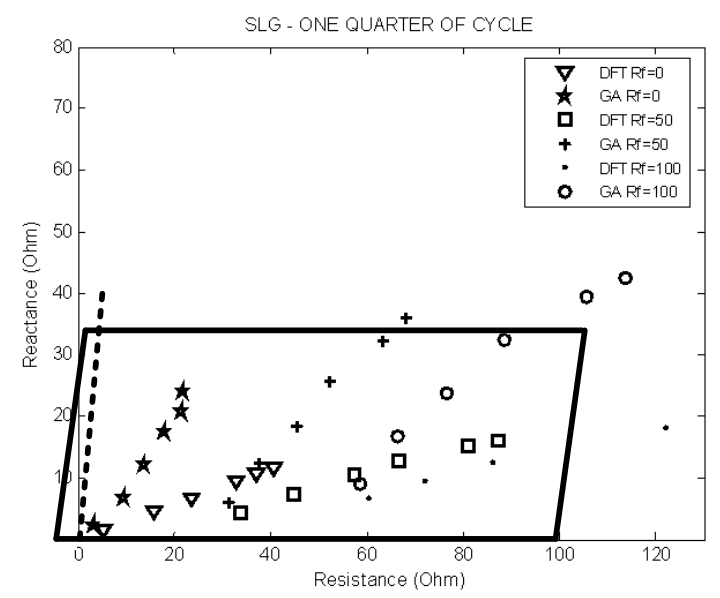

Figure 11: $\mathrm{R}-\mathrm{X}$ diagram for a SLG (AG) fault with 0,50 and 100 Ohms fault resistances and quarter cycle data window.

observed considering the GA technology. This behavior can also be found considering the distance estimations presented in Table 6 where the GA technique with a quarter cycle data window presented much smaller average errors if compared to the DFT.

It must be emphasized that, the GA methodology can present different results depending on its initialization. Considering this, in order to have a realistic result, each test was run individually 30 times and its average performance is presented in the tables.

The average running times for the proposed algorithm, considering fault detection, classification and location are $19.17 \mathrm{~ms}, 10.84 \mathrm{~ms}$ and $6.67 \mathrm{~ms}$ considering one, half and quarter cycle data windows, respectively.

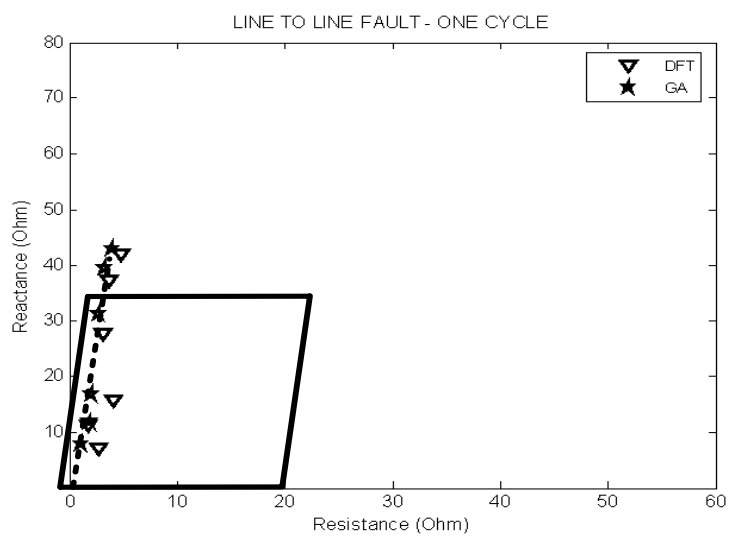

Figure 12: $R-X$ diagram for a double line $(A B)$ fault with 1 Ohm fault resistance and one cycle data window.

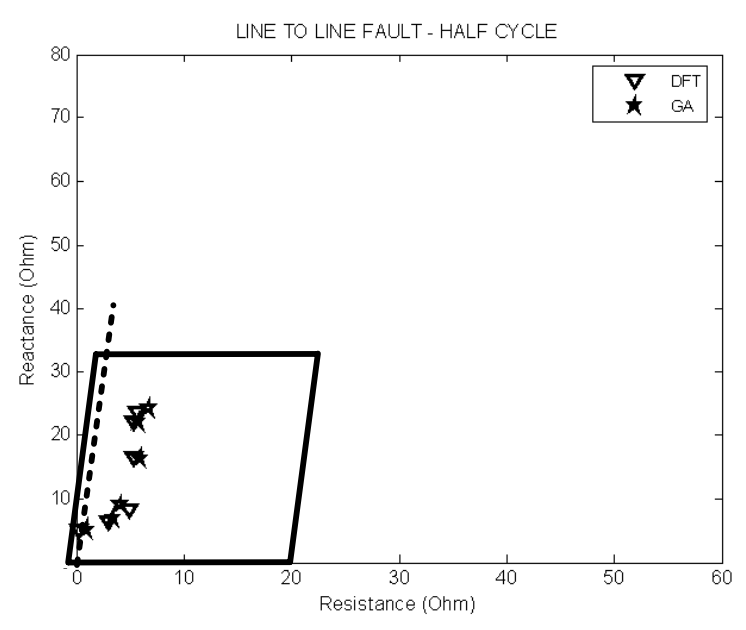

Figure 13: $R-X$ diagram for a double line $(A B)$ fault with 1 Ohm fault resistance and half cycle data window.

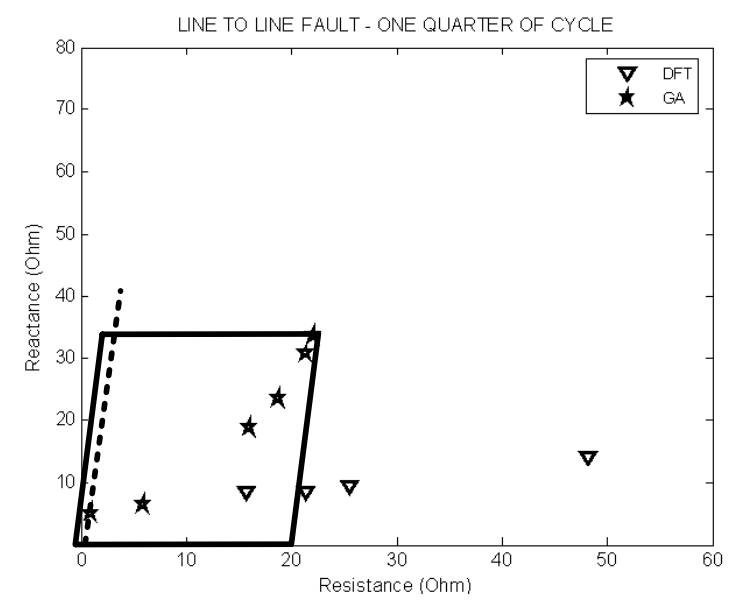

Figure 14: $\mathrm{R}-\mathrm{X}$ diagram for a double line $(A B)$ fault with 1 Ohm fault resistance and quarter cycle data window.

\subsection{Practical implementation}

This work has been developed on a simulation basis. However, it should be mentioned that an embedded methodology using FPGAs (Field-Programmable Gate Arrays) would be very suitable for this application. The system on chip concept makes intelligent digital distance relays possible in practice. A similar approach was implemented in Souza et al. (2008) for on-line application of a frequency relay (estimating frequency deviation, phasor magnitude and phase angle) with very good results, facing all the restraints concerning an on-line relay application. 


\section{CONCLUSIONS}

This work presented an efficient technique based on Genetic Algorithms applied to distance protection of power systems. Considering the study, the proposed methodology performed better compared to the traditional Discrete Fourier Transform method.

A basic algorithm for distance protection was tested and situations such as different types of faults, fault resistances, fault distances and size of the input data window were considered.

It can be concluded that the size of the window is very important for a good estimation. As far as distance protection is concerned, a shorter data window would give a faster response. In this context, the depreciation of the results when the size of the data window was made shorter could particularly be observed in the case of the DFT technique. The use of one, half and quarter cycle data windows showed an interesting comparison between the Genetic Algorithm and Discrete Fourier Transform with better performances in favor of the GA methodology. This is particularly important if we have in mind the times normally required for commercial relays (between one and two cycles) concerning the fault detection, classification and location for transmission lines.

\section{ACKNOWLEDGEMENT}

The authors acknowledge the Department of Electrical Engineering - Engineering School of São Carlos - University of São Paulo (Brazil), for the research facilities provided to conduct this project. Our thanks also to FAPESP - Fundação de Amparo à Pesquisa do Estado de São Paulo for the financial support.

\section{REFERENCES}

Alfuhaid, A. S. and El-Sayed, M. A. (1999). A recursive least-squares digital distance relaying algorithm. IEEE Trans. Power Delivery, v. 14, n. 4, pp. 1257-1262.

Altuve, F. H. J.; Diaz, V. and Vazquez, M. E. (1996). Fourier and Walsh digital filtering algorithms for distance protection. IEEE Trans. Power Delivery, v. 11, n. 1, pp. $457-462$.

ATP (1987). Alternative Transient Program. Leuven EMTP Center - Rule Book.

Chen, C. S.; Liu, C. W. and Jiang, J. A. (2006). Application of combined adaptive Fourier filtering tech- nique and fault detector to fast distance protection. IEEE Trans. Power Delivery, v. 21, n. 2, pp. 619626.

Girgis, A. A. and Brown, R. G. (1985). Adaptive Kalman filtering in computer relaying: fault classification using voltage models. IEEE Trans. Power Apparatus Systems, v. 104, n. 5, pp. 1167-1177.

Goldberge, D. (1989). Genetic algorithms in search. in: optimization and machine learning. AddisonWesely.

IEEE Std. C37.114 ${ }^{T M} \mathrm{~m}$ (2004). IEEE Guide for determining fault location on $\mathrm{AC}$ transmission and distribution lines. IEEE Publish, New York.

Macedo, R. A.; Silva, D. F.; Coury, D. V. and Carneiro, A. A. F. M. (2003). An evolutionary optimization approach to track voltage and current harmonics in electrical power systems. IEEE Power Eng. Soc. Gen. Meet., v. 2, pp. 1250-1255.

Osman, A. H. and Malik, O. P. (2001). Wavelet transform approach to distance protection of transmission lines. IEEE Power Eng. Soc. Summer Meet., 1, pp. 15-19.

Osman, A. H.; Abdelazim, T. and Malik, O. P. (2003a). Genetic algorithm approach for adaptive data window distance relaying. IEEE Power Eng. Soc. Gen. Meet., v. 3, pp. 1862-1867.

Osman, A. H.; Abdelazim, T. and Malik, O. P. (2003b). Adaptive distance relaying technique using on-line trained neural network. IEEE Power Eng. Soc. Gen. Meet., v. 3, pp. 13-17.

Pascual, H. O. and Rapallini, J. A. (2001). Behaviour of Fourier, cosine and sine filtering algorithms for distance protection, under severe saturation of the current magnetic transformer. IEEE Porto Power Tech Conf.

Phadke, A. G. and Thorp, J. S. (1988). Computer Relaying for Power Systems. John Wiley \& Sons.

Sidhu, T. S.; Ghotra, D. S. and Sachdev, M. S. (2002). An adaptive distance relay and its performance comparison with a fixed data window distance relay. IEEE Trans. Power Delivery, v. 17, n. 3, pp. 691-697.

Souza, S. A.; Oleskovicz, M.; Coury, D. V.; Silva, T. V.; Delbem, A. C. B. and Simões, E. V. (2008). FPGA Implementation of genetic algorithms for frequency estimation in power systems. IEEE PES Gen. Meet., Pittsburgh. 
Table 5: Distance estimation for a SLG (AG) fault with one, half and quarter data windows.

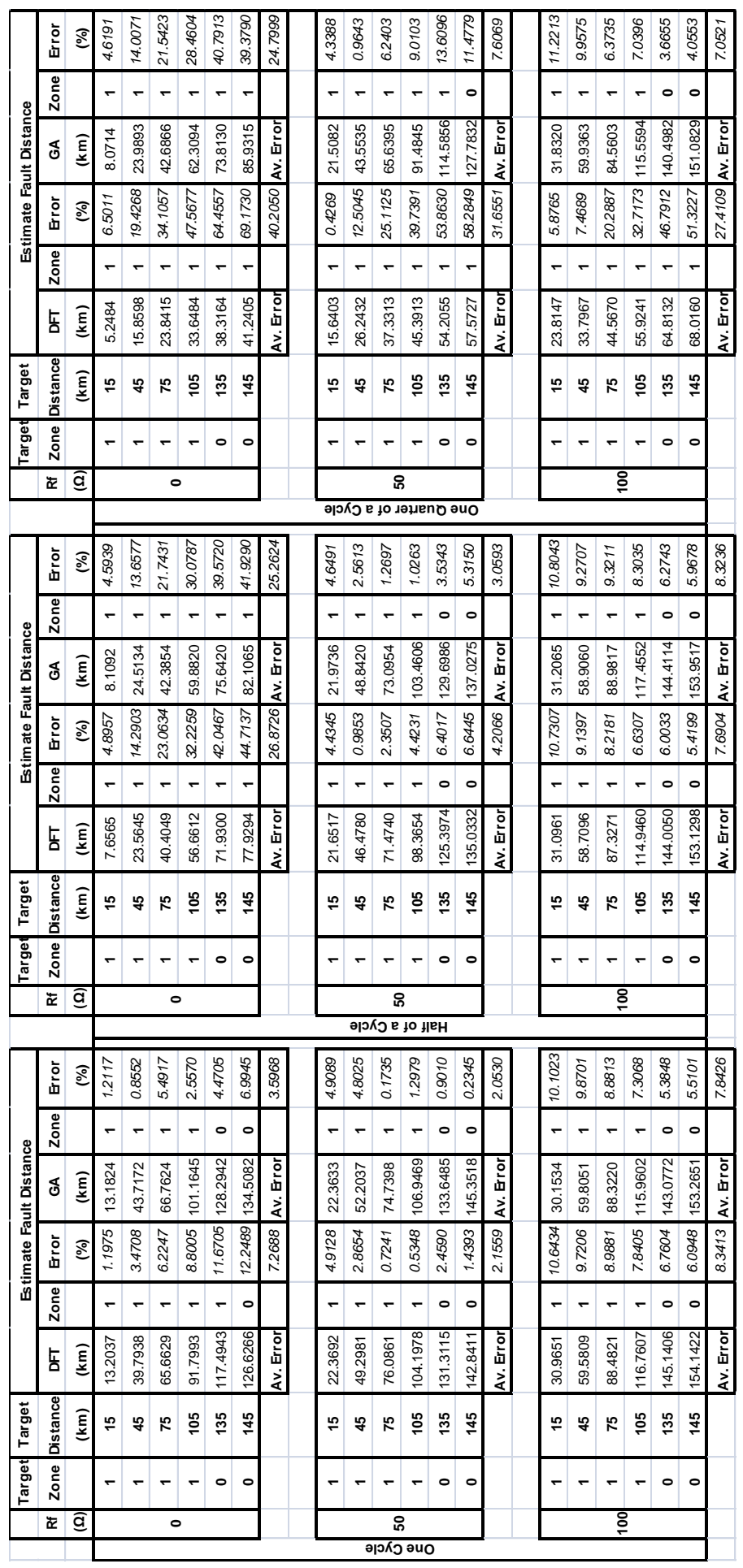


Table 6: Distance estimation for a double line $(A B)$ fault with one, half and quarter data windows.

\begin{tabular}{|c|c|c|c|c|c|c|c|c|c|}
\hline & \multirow{3}{*}{$\begin{array}{l}\text { Rf } \\
(\Omega)\end{array}$} & \multirow{2}{*}{$\begin{array}{c}\text { Target } \\
\text { Zone }\end{array}$} & \multirow{3}{*}{$\begin{array}{c}\text { Target } \\
\text { Distance } \\
(\mathbf{k m})\end{array}$} & \multicolumn{6}{|c|}{ Estimate Fault Distance } \\
\hline & & & & DFT & Zone & Error & GA & Zone & Error \\
\hline & & & & $(\mathrm{km})$ & & $(\%)$ & $(\mathrm{km})$ & & $(\%)$ \\
\hline \multirow{6}{*}{$\begin{array}{l}\frac{0}{0} \\
\text { Jे } \\
0 \\
0\end{array}$} & \multirow{6}{*}{1} & 1 & 15 & 25.4585 & 1 & 6.9723 & 28.3264 & 1 & 8.8843 \\
\hline & & 1 & 45 & 40.7422 & 1 & 2.8385 & 41.8901 & 1 & 2.0733 \\
\hline & & 1 & 75 & 56.5220 & 1 & 12.3187 & 60.3663 & 1 & 9.7558 \\
\hline & & 1 & 105 & 99.0110 & 1 & 3.9927 & 111.3835 & 1 & 4.2557 \\
\hline & & 0 & 135 & 133.4565 & 0 & 1.0290 & 140.4249 & 0 & 3.6166 \\
\hline & & 0 & 145 & 149.9801 & 0 & 3.3201 & 151.1982 & 0 & 4.1321 \\
\hline & & & & Av. Error & & 5.0785 & Av. Error & & 5.4529 \\
\hline \multirow{6}{*}{ 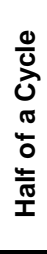 } & \multirow{6}{*}{1} & 1 & 15 & 18.2905 & 1 & 2.1937 & 18.0957 & 1 & 2.0638 \\
\hline & & 1 & 45 & 27.0539 & 1 & 11.9641 & 24.7307 & 1 & 13.5129 \\
\hline & & 1 & 75 & 29.4580 & 1 & 30.3613 & 31.9811 & 1 & 28.6793 \\
\hline & & 1 & 105 & 58.4590 & 1 & 31.0273 & 58.0636 & 1 & 31.2909 \\
\hline & & 0 & 135 & 78.5676 & 1 & 37.6216 & 78.5758 & 1 & 37.6161 \\
\hline & & 0 & 145 & 84.7035 & 1 & 40.1977 & 86.5001 & 1 & 38.9999 \\
\hline & & & & Av. Error & & 25.5609 & Av. Error & & 25.3604 \\
\hline \multirow{8}{*}{ 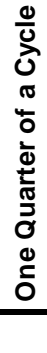 } & \multirow{7}{*}{1} & 1 & & & 1 & 103548 & & 1 & 2 5071 \\
\hline & & 1 & 15 & 30.5322 & 1 & 10.0040 & 18.8957 & 1 & 2.0971 \\
\hline & & 1 & 45 & 30.5676 & 1 & 9.6216 & 22.9438 & 1 & 14.7041 \\
\hline & & 1 & 75 & 34.0375 & 1 & 27.3083 & 67.5402 & 1 & 4.9732 \\
\hline & & 1 & 105 & 50.2944 & 1 & 36.4704 & 83.8399 & 1 & 14.1067 \\
\hline & & 0 & 135 & 72.9268 & 1 & 41.3821 & 109.6211 & 1 & 16.9193 \\
\hline & & 0 & 145 & 80.9051 & 1 & 42.7299 & 119.9412 & 1 & 16.7059 \\
\hline & & & & Av. Error & & 27.9779 & Av. Error & & 11.6677 \\
\hline
\end{tabular}

